\title{
Analytically tractable climate-carbon cycle feedbacks under 21st century anthropogenic forcing
}

\author{
Steven J. Lade ${ }^{1,2,3}$, Jonathan F. Donges ${ }^{1,4}$, Ingo Fetzer ${ }^{1,3}$, John M. Anderies ${ }^{5}$, Christian Beer ${ }^{3,6}$, \\ Sarah E. Cornell ${ }^{1}$, Thomas Gasser ${ }^{7}$, Jon Norberg ${ }^{1}$, Katherine Richardson ${ }^{8}$, Johan Rockström ${ }^{1}$, and \\ Will Steffen ${ }^{1,2}$ \\ ${ }^{1}$ Stockholm Resilience Centre, Stockholm University, Stockholm, Sweden \\ ${ }^{2}$ Fenner School of Environment and Society, The Australian National \\ University, Australian Capital Territory, Canberra, Australia \\ ${ }^{3}$ Bolin Centre for Climate Research, Stockholm University, Stockholm, Sweden \\ ${ }^{4}$ Potsdam Institute for Climate Impact Research, Potsdam, Germany \\ ${ }^{5}$ School of Sustainability and School of Human Evolution and Social \\ Change, Arizona State University, Tempe, Arizona, USA \\ ${ }^{6}$ Department of Environmental Science and Analytical Chemistry \\ (ACES), Stockholm University, Stockholm, Sweden \\ ${ }^{7}$ International Institute for Applied Systems Analysis, Laxenburg, Austria \\ ${ }^{8}$ Center for Macroecology, Evolution, and Climate, University of Copenhagen, \\ Natural History Museum of Denmark, Copenhagen, Denmark \\ Correspondence: Steven J. Lade (steven.lade@su.se)
}

Received: 1 September 2017 - Discussion started: 12 September 2017

Revised: 23 April 2018 - Accepted: 27 April 2018 - Published: 17 May 2018

\begin{abstract}
Changes to climate-carbon cycle feedbacks may significantly affect the Earth system's response to greenhouse gas emissions. These feedbacks are usually analysed from numerical output of complex and arguably opaque Earth system models. Here, we construct a stylised global climate-carbon cycle model, test its output against comprehensive Earth system models, and investigate the strengths of its climate-carbon cycle feedbacks analytically. The analytical expressions we obtain aid understanding of carbon cycle feedbacks and the operation of the carbon cycle. Specific results include that different feedback formalisms measure fundamentally the same climate-carbon cycle processes; temperature dependence of the solubility pump, biological pump, and $\mathrm{CO}_{2}$ solubility all contribute approximately equally to the ocean climate-carbon feedback; and concentration-carbon feedbacks may be more sensitive to future climate change than climate-carbon feedbacks. Simple models such as that developed here also provide "workbenches" for simple but mechanistically based explorations of Earth system processes, such as interactions and feedbacks between the planetary boundaries, that are currently too uncertain to be included in comprehensive Earth system models.
\end{abstract}

\section{Introduction}

The exchanges of carbon between the atmosphere and other components of the Earth system, collectively known as the carbon cycle, currently constitute important negative (dampening) feedbacks on the effect of anthropogenic carbon emissions on climate change. Carbon sinks in the land and the ocean each currently take up about one-quarter of anthro- pogenic carbon emissions each year (Le Quéré et al., 2016). These feedbacks are expected to weaken in the future, amplifying the effect of anthropogenic carbon emissions on climate change (Ciais et al., 2013). The degree to which they will weaken, however, is highly uncertain, with Earth system models predicting a wide range of land and ocean car- 


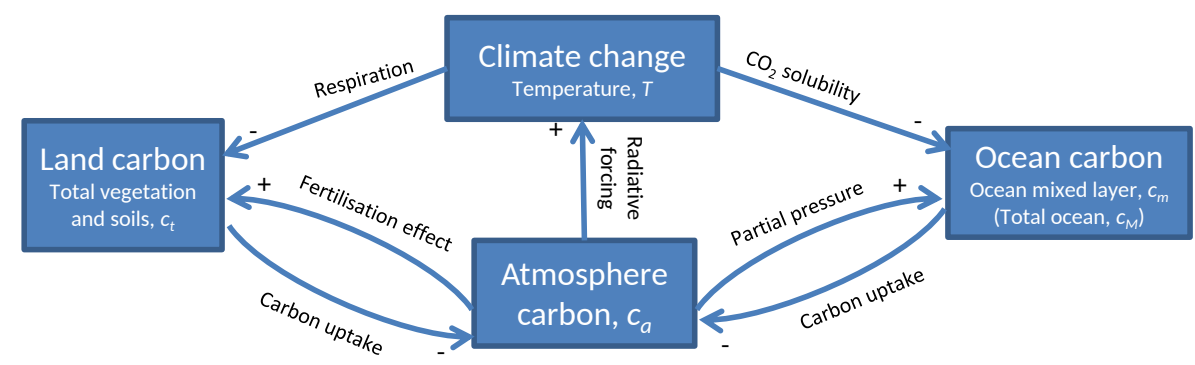

Figure 1. Climate-carbon cycle feedbacks and state variables as represented in the stylised model introduced in this paper. Carbon stored on land in vegetation and soils is aggregated into a single stock $c_{\mathrm{t}}$. Ocean mixed layer carbon, $c_{\mathrm{m}}$, is the only explicitly modelled ocean stock of carbon; though to estimate carbon cycle feedbacks we also calculate total ocean carbon (Eq. 7).

bon uptakes even under identical atmospheric concentration or emission scenarios (Joos et al., 2013).

Here, we develop a stylised model of the global carbon cycle and its role in the climate system to explore the potential weakening of carbon cycle feedbacks on policy-relevant timescales $(<100$ years) up to the year 2100 . Whereas comprehensive Earth system models are generally used for projections of climate, models of the Earth system of low complexity are useful for improving mechanistic understanding of Earth system processes and for enabling learning (Randers et al., 2016; Raupach, 2013). Compared to comprehensive Earth system models, our model has far fewer parameters, can be computed much more rapidly, can be more rapidly understood by both researchers and policymakers, and is even sufficiently simple that analytical results about feedback strengths can be derived. Compared to previous stylised models (Gregory et al., 2009; Joos et al., 1996; Meinshausen et al., 2011a, c; Gasser et al., 2017a), our model features simple mechanistic representations, as opposed to parametric fits to Earth system model output, of aggregated carbon uptake both on land and in the ocean. Our stylised and mechanistically based climate-carbon cycle model also offers a workbench for investigating the influence of mechanisms that are at present too uncertain, poorly defined, or computationally intensive to include in current Earth system models. Such stylised models are valuable for exploring the uncertain but potentially highly impactful Earth system dynamics such as interactions between climatic and social tipping elements (Lenton et al., 2008; Kriegler et al., 2009; Schellnhuber et al., 2016) and the planetary boundaries (Rockström et al., 2009; Steffen et al., 2015).

Analyses of climate-carbon cycle feedbacks conventionally distinguish four different feedbacks (Fig. 1) (Friedlingstein, 2015; Ciais et al., 2013). (i) In the land concentrationcarbon feedback, higher atmospheric carbon concentration generally leads to increased carbon uptake due to the fertilisation effect, in which increased $\mathrm{CO}_{2}$ stimulates primary productivity. (ii) In the ocean concentration-carbon feedback, physical, chemical, and biological processes interact to sink carbon. Atmospheric $\mathrm{CO}_{2}$ dissolves and dissociates in the upper layer of the ocean to then be transported deeper by physical and biological processes. The concentration-carbon feedbacks are generally negative, dampening the effects of anthropogenic emissions. (iii) In the land climate-carbon feedback, higher temperatures, along with other associated changes in climate, generally lead to decreased storage on land at the global scale, for example due to the increase in respiration rates with temperature. (iv) In the ocean climatecarbon feedback, higher temperatures generally lead to reduced carbon uptake by the ocean, for example due to decreasing solubility of $\mathrm{CO}_{2}$. The climate-carbon feedbacks are generally positive, amplifying the effects of carbon emissions.

We begin by introducing our stylised carbon cycle model and testing its output against historical observations and future projections of Earth system models. Having thus established the model's performance, we introduce different formalisms used to quantify climate-carbon cycle feedbacks and describe how they can be computed both numerically and analytically from the model. We use our results to analytically study the relative strengths of different climate-carbon cycle feedbacks and how they may change in the future, as well as to compare different feedback formalisms. We conclude by speculating on how this stylised model could be used as a "workbench" for studying a range of complex Earth system processes, especially those related to the biosphere.

\section{Model formulation}

There is well-developed literature on stylised models used for gaining a deeper understanding of Earth system dynamics and even for successfully emulating the outputs of comprehensive coupled atmosphere-ocean and carbon cycle models (Anderies et al., 2013; Gregory et al., 2009; Joos et al., 1996; Meinshausen et al., 2011a, c; Gasser et al., 2017a). We developed a combination of existing models and new formulations to construct a global climate-carbon cycle model with the following characteristics.

1. The model includes processes relevant to the carbon cycle and its interaction with climate on the policy- 
relevant timescale of the present to the year 2100 . Stylised carbon cycle models often do not, for example, include explicit representations of the solubility or biological pumps.

2. The model produces quantitatively plausible output for carbon stocks and temperature changes.

3. All parameters have a direct biophysical or biogeochemical interpretation, although these parameters may be at an aggregated scale (for example, a parameter for the net global fertilisation effect, rather than leaf physiological parameters). We avoid models or model components constructed by purely parametric fits, such as impulse response functions, to historical data or projections of Earth system models (Kamiuto, 1994; Gasser et al., 2017b; Joos et al., 1996; Harman et al., 2011; Gregory et al., 2009; Meinshausen et al., 2011a).

4. The model is sufficiently simple that calculation of the model's feedback strengths is readily analytically tractable. This tractability may come at the expense of complexity, for example multiple terrestrial carbon compartments, or accuracy at millennial or longer timescales (Lenton, 2000; Randers et al., 2016).

Building on the work of Anderies et al. (2013), we constructed a simple model with globally aggregated stocks of atmospheric carbon in the form of carbon dioxide, $c_{\mathrm{a}}$; terrestrial carbon, including vegetation and soil carbon, $c_{\mathrm{t}}$; and dissolved inorganic carbon (DIC) in the ocean mixed layer, $c_{\mathrm{m}}$. The model's fourth state variable is global mean surface temperature relative to pre-industrial, $\Delta T=T-T_{0}$. Compared to Anderies et al. (2013), our model includes more realistic representation of terrestrial and ocean processes but without increase in model complexity, as well as time lags for climate response to $\mathrm{CO}_{2}$.

We now describe the dynamics of the land carbon stock, the ocean carbon stock, and atmospheric carbon and temperature in our model.

\subsection{Land}

Net primary production (NPP) is the net uptake of carbon from the atmosphere by plants through photosynthesis. NPP is expected to increase with concentration of atmospheric carbon dioxide $c_{\mathrm{a}}$. A simple parameterisation of this socalled fertilisation effect is "Keeling's formula" for global NPP (Bacastow et al., 1973; Alexandrov et al., 2003):

$\operatorname{NPP}\left(c_{\mathrm{a}}\right)=\operatorname{NPP}_{0}\left(1+K_{\mathrm{C}} \log \frac{c_{\mathrm{a}}}{c_{\mathrm{a} 0}}\right)$.

Throughout this article, the subscript " 0 " denotes the value of the quantity at a pre-industrial equilibrium, and "log" denotes natural logarithm. Keeling's formula incorporates all climate-change-related effects on global NPP occurring simultaneously with carbon dioxide changes, for example, precipitation and temperature effects, in addition to fertilisation effects. The curvature of the log function represents limitations to NPP such as changing carbon-use efficiency (Körner, 2003) or nutrient limitations (Zaehle et al., 2010). Constant climate sensitivity is also a key assumption, otherwise the relative weight of climate and $\mathrm{CO}_{2}$ effects on NPP would change.

At the same time, carbon loss from the world's soils through respiration, $R$, is expected to increase at higher global mean surface temperature, $\Delta T$. We approximate the net temperature response of global soil respiration using the $Q_{10}$ formalism $R(\Delta T)=R_{0} Q_{\mathrm{R}}^{\Delta T / 10} c_{\mathrm{t}} / c_{\mathrm{t} 0}$ (Xu and Shang, 2016), where $Q_{\mathrm{R}}$ is the proportional increase in respiration for a $10 \mathrm{~K}$ temperature increase. We assume that preindustrial soil respiration is balanced by pre-industrial NPP, $R_{0}=\mathrm{NPP}_{0}$. To avoid introducing multiple pools of carbon into the model, we also have to assume that global soil respiration is proportional to total land carbon (rather than soil carbon). Respiration in our model also implicitly includes other carbon-emitting processes such as wildfires or insect disturbances.

It follows that the change in global terrestrial carbon storage is

$\frac{\mathrm{d} c_{\mathrm{t}}}{\mathrm{d} t}=\mathrm{NPP}_{0}\left(1+K_{\mathrm{C}} \log \frac{c_{\mathrm{a}}}{c_{\mathrm{a} 0}}\right)-\frac{\mathrm{NPP}_{0}}{c_{\mathrm{t} 0}} Q_{\mathrm{R}}^{\Delta T / 10} c_{\mathrm{t}}-\mathrm{LUC}(t)$.

In this expression we have also included loss of terrestrial carbon due to land use emissions $\operatorname{LUC}(t)$. We rearrange this expression to give

$\frac{\mathrm{d} c_{\mathrm{t}}}{\mathrm{d} t}=\frac{\mathrm{NPP}_{0}}{c_{\mathrm{t} 0}} Q_{\mathrm{R}}^{\Delta T / 10}\left[K\left(c_{\mathrm{a}}, \Delta T\right)-c_{\mathrm{t}}\right]-\operatorname{LUC}(t)$,

where the terrestrial carbon carrying capacity is

$K\left(c_{\mathrm{a}}, \Delta T\right)=\frac{1+K_{\mathrm{C}} \log \frac{c_{\mathrm{a}}}{c_{\mathrm{a} 0}}}{Q_{\mathrm{R}}^{\Delta T / 10}} c_{\mathrm{t} 0}$.

For model simplicity, we do not explicitly model factors affecting terrestrial carbon uptake such as seasonality, species interactions, species functionality, migration, and regional variability.

\subsection{Ocean}

In the upper-ocean mixed layer, mixing processes allow exchange of carbon dioxide with the atmosphere. The solubility and biological pumps then transport carbon from the mixed layer into the deep ocean. Since the residence time of deep ocean carbon is several centuries, we explicitly only model the dynamics of upper-ocean carbon while the deep ocean is treated merely as an extremely large carbon reservoir. We include the effects of ocean carbon chemistry, the solubility 
and biological pumps, and ocean-atmosphere diffusion on upper-ocean mixed layer carbon.

Ocean uptake of carbon dioxide from the atmosphere is chemically buffered by other species of DIC such as $\mathrm{HCO}_{3}^{-}$ and $\mathrm{CO}_{3}^{2-}$, which are produced when dissolved $\mathrm{CO}_{2}$ reacts with water. The reaction of $\mathrm{CO}_{2}$ with water, producing these other species, reduces the partial pressure of $\mathrm{CO}_{2}$ in water allowing for more ocean $\mathrm{CO}_{2}$ uptake before equilibrium with the atmosphere is achieved. The Revelle factor, $r$, is defined as the ratio of the proportional change in carbon dioxide content to the proportional change in total DIC (Sabine et al., 2004; Goodwin et al., 2007). For simplicity, we assume a constant Revelle factor, except for the temperature dependence, $D_{T}$, of the solubility of $\mathrm{CO}_{2}$ in seawater. Therefore $\mathrm{CO}_{2}$ diffuses between the atmosphere and ocean mixed layer at a rate proportional to

$c_{\mathrm{a}}-p\left(c_{\mathrm{m}}, \Delta T\right)$,

where

$p\left(c_{\mathrm{m}}, \Delta T\right)=c_{\mathrm{a} 0}\left(\frac{c_{\mathrm{m}}}{c_{\mathrm{m} 0}}\right)^{r} \frac{1}{1-D_{T} \Delta T}$,

since at pre-industrial equilibrium $p\left(c_{\mathrm{m} 0}, 0\right)=c_{\mathrm{a} 0}$.

There are two main mechanisms by which carbon is transported out of the upper-ocean mixed layer into the deep ocean stocks: the solubility and biological pumps. In the solubility pump, overturning circulations exchange mixed layer and deep ocean water. We assume that the large size of the deep ocean means its carbon concentrations are negligibly changed over the 100-year timescales relevant for the model. The net transport of carbon to the lower ocean by the solubility pump can therefore be represented by

$w_{0}\left(1-w_{\mathrm{T}} \Delta T\right)\left(c_{\mathrm{m}}-c_{\mathrm{m} 0}\right)$,

where $w_{0}$ is the (proportional) rate at which mixed layer ocean water is exchanged with the deep ocean and $w_{T}$ parameterises weakening of the overturning circulation that is expected to occur with future climate change (Collins et al., 2013).

The biological pump refers to the sinking of biomass and organic carbon produced in the upper ocean to deeper ocean layers (Volk and Hoffert, 1985). In the models on which the IPCC reports are based, a weakening of the biological pump is predicted under climate change, mostly due to a decrease in primary production, in turn due to increases in thermal stratification of ocean waters (Bopp et al., 2013). We represent this climate-induced weakening in a single approximately linear factor, so that the rate of carbon transported out of the upper-ocean mixed layer by the biological pump to lower deep sea layers is given by

$B(\Delta T)=B_{0}\left(1-B_{T} \Delta T\right)$.

As on land, we assume a pre-industrial equilibrium at which the biological pump was balanced by transport of carbon back to the mixed layer by ocean circulation. We neglect deposition of organic carbon to the sea floor and the long timescale variations in the biological pump that may have contributed to glacial-interglacial cycles (Sigman and Boyle, $2000)$. We therefore add an additional term $B(\Delta T)-B(0)$ to the transport of carbon from the ocean mixed layer to the deep ocean. Organic carbon that does not sink to the deep ocean is rapidly respired back to forms of inorganic carbon; the ocean mixed layer stock of organic carbon is therefore small, around $3 \mathrm{PgC}$ (Ciais et al., 2013), and we do not count it in the model's carbon balance.

By combining the expressions for the solubility and biological pumps with ocean-atmosphere carbon dioxide diffusion, we obtain the rate of change of ocean mixed layer DIC, $c_{\mathrm{m}}$ :

$$
\begin{aligned}
\frac{\mathrm{d} c_{\mathrm{m}}}{\mathrm{d} t} & =\frac{D c_{\mathrm{m} 0}}{r p\left(c_{\mathrm{m} 0}, 0\right)}\left(c_{\mathrm{a}}-p\left(c_{\mathrm{m}}, \Delta T\right)\right) \\
& -w_{0}\left(1-w_{T} \Delta T\right)\left(c_{\mathrm{m}}-c_{\mathrm{m} 0}\right)-B(\Delta T)+B(0) .
\end{aligned}
$$

The coefficient of the first term was chosen such that $1 / D$ is the timescale on which carbon dioxide diffuses between the atmosphere and the ocean mixed layer (that is, the derivative of the first term with respect to $c_{\mathrm{m}}$, evaluated at the preindustrial equilibrium, is $D$ ).

The carbon content of the deep ocean does not explicitly enter Eq. (6). To evaluate ocean carbon feedbacks, however, we require the change in total ocean carbon content $c_{M}$ compared to pre-industrial conditions. We calculate this as ocean mixed layer carbon plus carbon transported to the deep ocean by the solubility and biological pumps:

$$
\begin{aligned}
\Delta c_{\mathrm{M}} & =\Delta c_{\mathrm{m}}+\int^{t}\left[w_{0}\left(1-w_{T} \Delta T\right)\left(c_{\mathrm{m}}(t)-c_{\mathrm{m} 0}\right)\right. \\
& +B(\Delta T)-B(0)] \mathrm{d} t .
\end{aligned}
$$

We do not explicitly model factors such as the thickness of ocean stratification layers, spatial variation of stratification, nutrient limitations to NPP, or changes in ocean circulation due to wind forcing, freshwater forcing, or sea-ice processes (Bernardello et al., 2014).

\subsection{Atmosphere}

We define $c_{\mathrm{s}}$ to be the total carbon in our "system", comprised of carbon stocks in the ocean mixed layer, atmosphere, and terrestrial biosphere, that is

$c_{\mathrm{a}}+c_{\mathrm{t}}+c_{\mathrm{m}}=c_{\mathrm{s}}$.

The only processes that affect the total carbon are human emissions of fossil carbon into the atmosphere, $e(t)$, and export of carbon into the deep ocean by the solubility and biological pumps, giving 

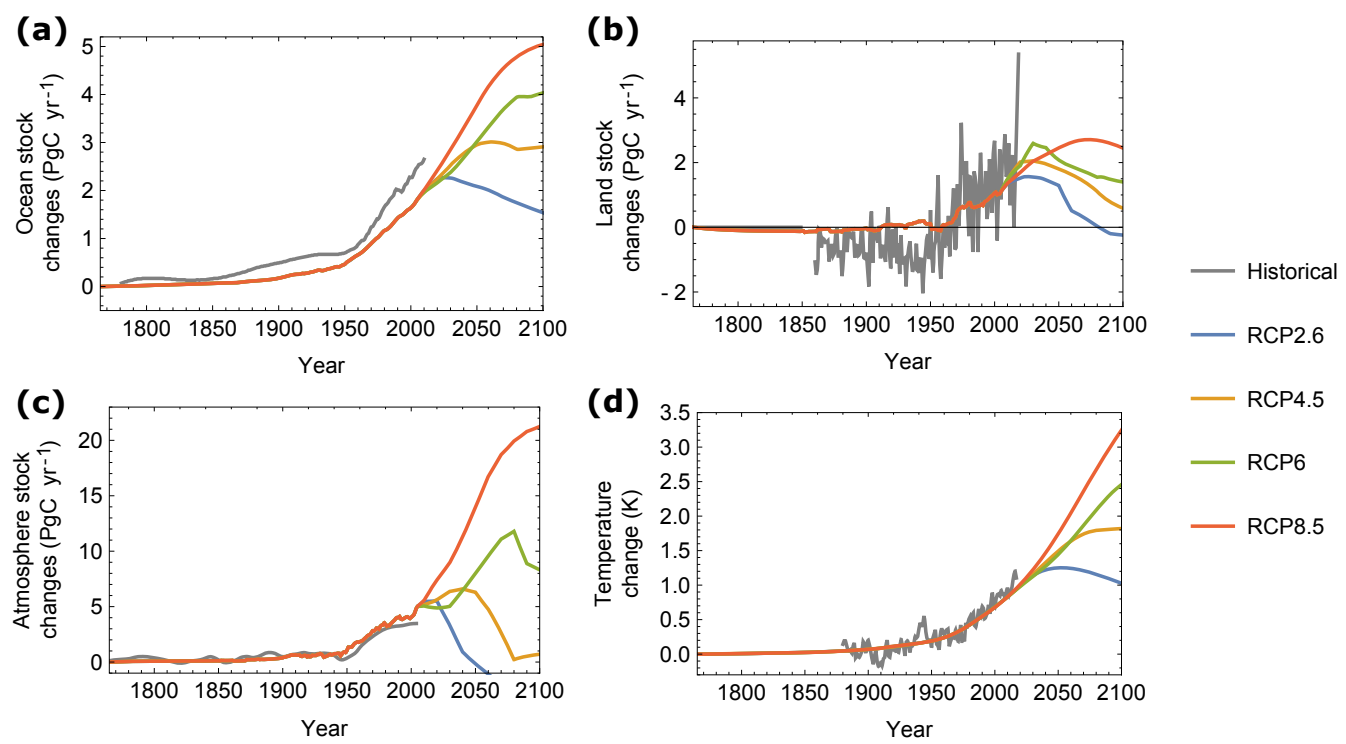

Figure 2. Model output under forcing from different RCP scenarios: (a) ocean carbon stock change, (b) land carbon stock changes, (c) atmospheric carbon stock change, and (d) global mean surface temperature change. Historical changes in carbon stocks are from Le Quéré et al. (2016) and historical temperature anomalies are from NOAA (2018). The historical temperature dataset of NOAA (2018), which is relative to the period 1901-2000, has been offset to match the model's average temperature anomaly over the same period.

$$
\begin{aligned}
\frac{\mathrm{d} c_{\mathrm{s}}}{\mathrm{d} t} & =e(t)-w_{0}\left(1-w_{T} \Delta T\right)\left(c_{\mathrm{m}}-c_{\mathrm{m} 0}\right) \\
& -(B(\Delta T)-B(0)),
\end{aligned}
$$

in which the initial value of $c_{\mathrm{s}}$ is $c_{\mathrm{a} 0}+c_{\mathrm{t} 0}+c_{\mathrm{m} 0}$. To obtain the dynamics of atmosphere carbon stocks, we therefore solve the differential Eq. (9) and then use the carbon balance Eq. (8) to find $c_{\mathrm{a}}$.

Increasing atmospheric carbon dioxide levels $c_{\mathrm{a}}$ cause a change in global mean surface temperature, $\Delta T$, compared to its pre-industrial level. To model the response of $\Delta T$, we follow the formulation of Kellie-Smith and Cox (2011), which includes a logarithmic response as per the Arrhenius law and a delay of timescale $\tau$. Physically, this time delay is primarily due to the heat capacity of the ocean.

$$
\frac{\mathrm{d} \Delta T}{\mathrm{~d} t}=\frac{1}{\tau}\left(\frac{\lambda}{\log 2} \log \left(\frac{c_{\mathrm{a}}}{c_{\mathrm{a} 0}}\right)-\Delta T\right)
$$

The climate sensitivity $\lambda$ specifies the increase in temperature in response to a doubling of atmospheric carbon dioxide levels. The climate sensitivity accounts for energy balance feedbacks such as from clouds and albedo. We use the transient climate sensitivity (Collins et al., 2013) as this specifies the response of the climate system over an approximately 100year timescale (see Sect. 3).

\section{Model parameterisation and validation}

Our climate-carbon cycle model has 12 parameters, four state variables, and three nontrivial initial conditions (by def- inition, the initial value of $\Delta T$ is 0 ). We choose to parameterise each process with the best available knowledge about that process, rather than try to force the model to fit historical data. This is in line with our stated model purposes of understanding and learning, rather than prediction. Parameters for the response of climate to carbon dioxide $(\lambda, \tau)$ and two parameters of the response of the ocean to changing temperature $\left(B_{T}\right.$ and $w_{\mathrm{T}}$ ) were set based on the output of atmosphere-ocean global circulation models. For the climate sensitivity $\lambda$, transient climate response was used. All other parameters are based on historical observations of the global carbon cycle (Table 1).

Unless otherwise noted, we perform emissions-based model runs using harmonised historical data and future RCP scenarios on fossil fuel emissions $[e(t)]$ and land use emissions $[\operatorname{LUC}(t)]$ (Meinshausen et al., 2011b). While the focus of our study is on future climate change, from the present day until 2100, we begin simulations in 1750 to compare our model against historical observations. Time series of the model output are displayed in Fig. 2. Model solutions were approximated in continuous time.

\section{Feedback analysis}

Our climate-carbon cycle model is sufficiently simple that the strengths of its feedbacks can be estimated analytically. Such computations are useful since the resulting symbolic expressions can be used to identify how parameters of interest affect feedback strengths and model dynamics. In this section we introduce definitions of feedback strengths, cal- 
Table 1. Model parameters.

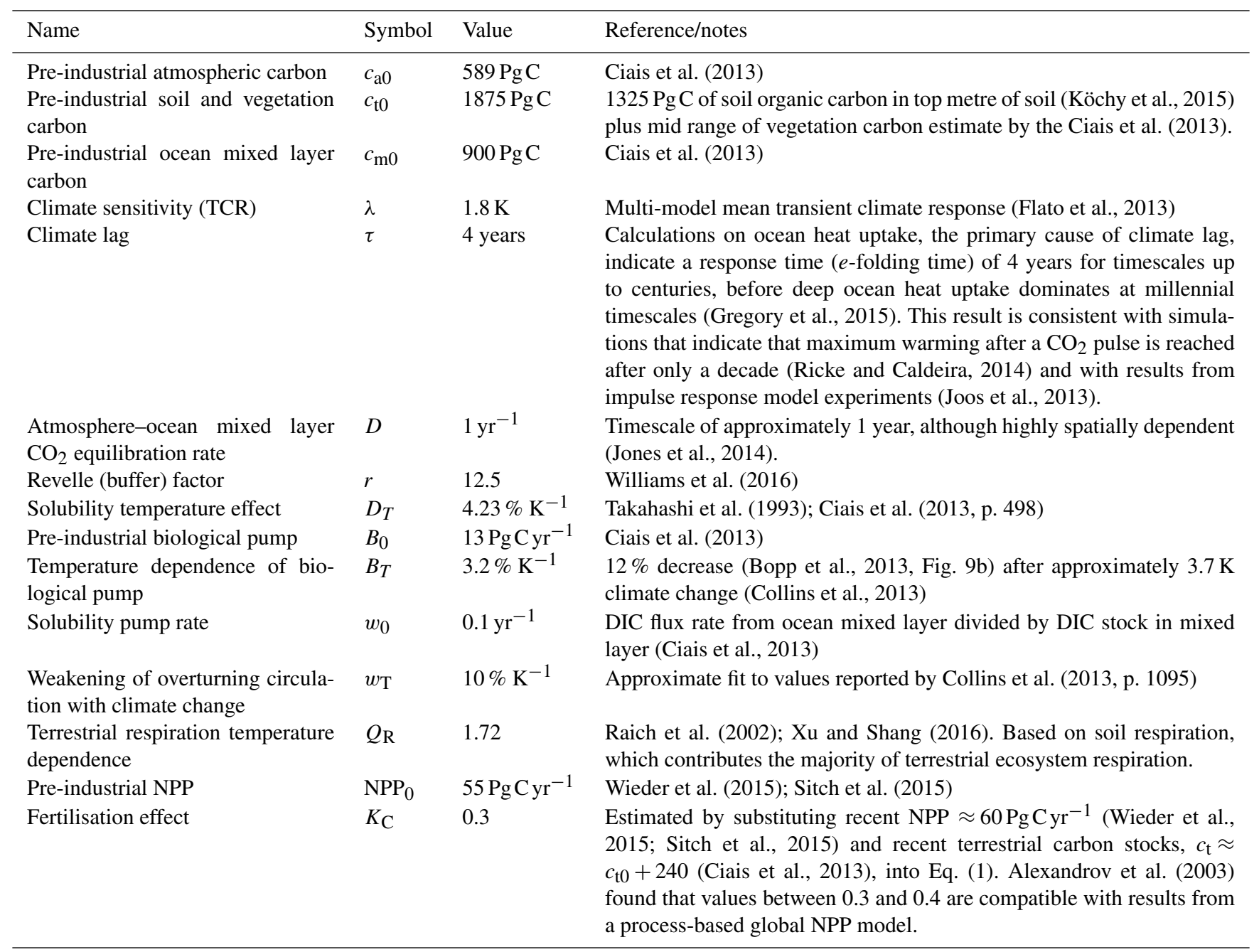

culate climate-carbon cycle feedbacks analytically and numerically, and estimate feedback non-linearities.

\subsection{Definitions}

There are multiple measures of carbon cycle feedbacks currently in use. We here review three of the most common measures.

Consider an emission of $E \mathrm{Pg} C$ over some time period to the atmosphere. In the absence of carbon cycle feedbacks, the atmospheric carbon content would increase by $\Delta c_{\mathrm{a}}^{\text {off }} \equiv E$. With a feedback switched on, the atmospheric carbon content would actually change by $\Delta c_{\mathrm{a}}^{\text {on }}$. The feedback factor is (Zickfeld et al., 2011)

$F=\frac{\Delta c_{\mathrm{a}}^{\mathrm{on}}}{\Delta c_{\mathrm{a}}^{\mathrm{off}}}$
Out of the total atmospheric carbon change $\Delta c_{\mathrm{a}}^{\text {on }}$, the carbon cycle feedback contributes (Hansen et al., 1984)

$\Delta c_{\mathrm{a}}^{\text {feedback }}=\Delta c_{\mathrm{a}}^{\text {on }}-\Delta c_{\mathrm{a}}^{\text {off }}$.

Gain is the change in a feedback to atmospheric carbon content caused by changes in atmospheric carbon content:

$g=\frac{\Delta c_{\mathrm{a}}^{\text {feedback }}}{\Delta c_{\mathrm{a}}^{\text {on }}}$.

Gain and feedback factor are related by

$F=\frac{1}{1-g}$.

An alternative formalism, introduced by Friedlingstein et al. (2006), allows feedbacks to be characterised from carbon cycle model output. Climate models are not required, except as a forcing to the carbon cycle model. The formalism relates the changes in terrestrial and marine carbon stocks to 
changes in global mean temperature and atmospheric carbon dioxide as follows:

$$
\begin{aligned}
& \Delta c_{\mathrm{t}}=\beta_{\mathrm{L}} \Delta c_{\mathrm{a}}+\gamma_{\mathrm{L}} \Delta T \\
& \Delta c_{\mathrm{M}}=\beta_{\mathrm{O}} \Delta c_{\mathrm{a}}+\gamma_{\mathrm{O}} \Delta T .
\end{aligned}
$$

Here the $\beta_{\mathrm{L}}$ and $\beta_{\mathrm{O}}$ feedback parameters are the land and ocean, respectively, carbon sensitivities to atmospheric carbon dioxide changes $\Delta c_{\mathrm{a}}$. Likewise, $\gamma_{\mathrm{L}}$ and $\gamma_{\mathrm{O}}$ are the land and ocean, respectively, carbon sensitivities to temperature changes $\Delta T$. Note that $c_{\mathrm{M}}$ denotes the total marine carbon stock, both mixed layer and deep ocean. The differences $\Delta c_{\mathrm{a}}$, etc., are usually calculated over the duration of a simulation. To isolate the $\beta$ and $\gamma$ feedback parameters, simulations are conducted with biogeochemical coupling only and with radiative coupling only (Gregory et al., 2009).

In both the formalisms introduced thus far, the feedback measures are calculated by examining the changes in carbon stocks at the end point of model simulations. In contrast, Boer and Arora (2009) estimate sensitivities $\Gamma$ and $B$ of the instantaneous carbon fluxes from atmosphere to land and ocean:

$$
\begin{gathered}
\frac{\mathrm{d} c_{\mathrm{t}}}{\mathrm{d} t}=B_{\mathrm{L}} \Delta c_{\mathrm{a}}+\Gamma_{\mathrm{L}} \Delta T \\
\frac{\mathrm{d} c_{\mathrm{M}}}{\mathrm{d} t}=B_{\mathrm{O}} \Delta c_{\mathrm{a}}+\Gamma_{\mathrm{O}} \Delta T .
\end{gathered}
$$

These feedback parameters $B$ and $\Gamma$ are usually computed for all time points during a simulation, again using biogeochemically coupled and radiatively coupled simulations.

The two sets of parameters $(B, \Gamma)$ and $(\beta, \gamma)$ are related by

$$
\begin{aligned}
& \beta \Delta c_{\mathrm{a}}=\int B \Delta c_{\mathrm{a}} \mathrm{d} t \\
& \gamma \Delta T=\int \Gamma \Delta T \mathrm{~d} t .
\end{aligned}
$$

Accordingly, Boer and Arora (2013) refer to $B$ and $\Gamma$ as direct feedback parameters and to $\beta$ and $\gamma$ as time-integrated feedback parameters.

\subsection{Analytical feedback strengths based on equilibrium changes}

Analytical approximations to the strengths of carbon cycle feedbacks in our model require choosing a timescale on which the feedbacks will be calculated. Numerically estimated feedback factors (Eq. 11) and time-integrated feedback parameters (Eqs. 15-16) are conventionally calculated using carbon stock changes over 100 years or more. Responses on the longest timescales of our model are therefore most relevant if our analytical approximations are to approximate numerically calculated values. While recognising that the Earth's climate system is presently far from equilibrium, we use changes in the equilibrium state of the model to approximate model responses over long timescales.

We analytically calculate the gains associated with each of the feedback loops in Fig. 1 as follows. We calculate the sensitivity (mathematically, partial derivative) of the equilibrium value of each quantity in the feedback loop with respect to the preceding quantity in the loop. We form the product of the derivatives (as per the chain rule of differentiation) to estimate the gain of that feedback loop. For example, to calculate the land climate-carbon gain we calculate the sensitivity of equilibrium temperature with respect to changes in atmospheric carbon content $\left(\partial T^{*} / \partial c_{\mathrm{a}}\right)$, multiplied by the sensitivity of equilibrium terrestrial carbon with respect to changes in temperature $\left(\partial c_{\mathrm{t}}^{*} / \partial T\right)$, multiplied by the sensitivity of equilibrium atmospheric carbon with respect to changes in terrestrial carbon $\left(\partial c_{\mathrm{a}}^{*} / \partial c_{\mathrm{t}}\right)$.

Land climate-carbon equilibrium gain.

$g_{\mathrm{TL}}^{*} \equiv \frac{\partial T^{*}}{\partial c_{\mathrm{a}}} \frac{\partial c_{\mathrm{t}}^{*}}{\partial T} \frac{\partial c_{\mathrm{a}}^{*}}{\partial c_{\mathrm{t}}}$

Land concentration-carbon equilibrium gain.

$g_{\mathrm{L}}^{*} \equiv \frac{\partial c_{\mathrm{t}}^{*}}{\partial c_{\mathrm{a}}} \frac{\partial c_{\mathrm{a}}^{*}}{\partial c_{\mathrm{t}}}$

Ocean climate-carbon equilibrium gain.

$g_{\mathrm{TO}}^{*} \equiv \frac{\partial T^{*}}{\partial c_{\mathrm{a}}} \frac{\partial c_{\mathrm{M}}}{\partial T} \frac{\partial c_{\mathrm{a}}^{*}}{\partial c_{\mathrm{M}}}$

Ocean concentration-carbon equilibrium gain.

$g_{\mathrm{O}}^{*} \equiv \frac{\partial c_{\mathrm{M}}}{\partial c_{\mathrm{a}}} \frac{\partial c_{\mathrm{a}}^{*}}{\partial c_{\mathrm{M}}}$

The subscript $T$ denotes that the feedback involves temperature. Asterisks $(*)$ denote equilibrium quantities. From these gains, the feedback factors $F_{\mathrm{TL}}^{*}, F_{\mathrm{L}}^{*}, F_{\mathrm{TO}}^{*}$, and $F_{\mathrm{O}}^{*}$ can be calculated using Eq. (14). We label these gain and feedback factors $g^{*}$ and $F^{*}$, respectively, to denote they are based on an equilibrium approximation, not directly from transient simulations as estimated by Zickfeld et al. (2011).

The derivatives of $c_{\mathrm{a}}^{*}$ are trivial to calculate: by carbon balance, $\frac{\partial c_{\mathrm{a}}^{*}}{\partial c_{\mathrm{t}}}=\frac{\partial c_{\mathrm{a}}^{*}}{\partial c_{\mathrm{M}}}=-1$. To calculate the derivatives of $c_{\mathrm{T}}^{*}$, we set $0=\frac{\mathrm{d} c_{\mathrm{t}}}{\mathrm{d} t}$, solve for $c_{\mathrm{t}}$, and calculate the necessary derivatives. A similar procedure provides $\frac{\partial T^{*}}{\partial c_{\mathrm{a}}}$.

The remaining derivatives are $\frac{\partial c_{M}}{\partial T}$ and $\frac{\partial c_{M}}{\partial c_{\mathrm{a}}}$. Carbon sunk into the deep ocean is substantial and cannot be neglected. Deep ocean carbon storage equilibrates on timescales of millennia or more, however, far longer than the timescales of interest in this model (we therefore write derivatives of $c_{\mathrm{M}}$ rather than $c_{\mathrm{M}}^{*}$ ). We therefore cannot use the same equilibrium approach as for the other variables. Instead, we derive approximations to Eq. (7) as follows. First, we observe that in the SRES A2 scenario used below, both $c_{\mathrm{m}}(t)$ and $\Delta T(t)$ can be approximated as linear increases, starting at $c_{\mathrm{m}}=c_{\mathrm{m} 0}$ and $\Delta T=0$, respectively, over a time interval $t_{\text {lin }}$. We estimate this time interval by $t_{\text {lin }}=\left(c_{\mathrm{m}}\left(t_{\text {end }}\right)-c_{\mathrm{m} 0}\right) / c_{\mathrm{m}}^{\prime}\left(t_{\text {end }}\right)$ us- 
Table 2. Model validation. Historical changes are carbon stocks in 2011 relative to stocks in 1750 (Ciais et al., 2013) and temperatures in 2012 relative to temperatures in 1880 (Hartmann et al., 2013). Predicted future changes are carbon stocks in 2100 compared to 2012 (Collins et al., 2013) and global mean surface temperature (GMST) averaged over 2081-2100 relative to 1986-2005 (Collins et al., 2013), under the range of RCP scenarios.

\begin{tabular}{lrrrrrr}
\hline & \multicolumn{2}{c}{$\begin{array}{c}\text { Ocean carbon changes (Pg C) } \\
\text { IPCC AR5 }\end{array}$} & $\begin{array}{c}\text { Land carbon changes (Pg C) } \\
\text { Model result }\end{array}$ & IPCC AR5 & Model result & \multicolumn{2}{c}{$\begin{array}{c}\text { GMST change, } \Delta T(\mathrm{~K}) \\
\text { IPCC AR5 }\end{array}$} & Model result \\
\hline Historical & $155 \pm 30$ & 95 & $-30 \pm 45$ & 26 & $0.85[0.65$ to 1.06$]$ & 0.82 \\
RCP2.6 & $150[105$ to 185$]$ & 174 & $65[-50$ to 195$]$ & 67 & $1.0[0.3$ to 1.7$]$ & 0.5 \\
RCP4.5 & $250[185$ to 400$]$ & 243 & $230[55$ to 450$]$ & 135 & $1.8[1.1$ to 2.6$]$ & 1.2 \\
RCP6 & $295[265$ to 335$]$ & 278 & $200[-80$ to 370$]$ & 168 & $2.2[1.4$ to 3.1$]$ & 1.7 \\
RCP8.5 & $400[320$ to 635$]$ & 340 & $180[-165$ to 500$]$ & 207 & $3.7[2.6$ to 4.8$]$ & 2.4 \\
\hline
\end{tabular}

ing the value $c_{\mathrm{m}}$ and gradient $c_{\mathrm{m}}^{\prime}$ at the end of the simulation period. We obtain

$$
\begin{aligned}
\Delta c_{\mathrm{M}} & \approx c_{\mathrm{m}}-c_{\mathrm{m} 0}+w_{0}\left(\frac{1}{2}-\frac{1}{3} w_{\mathrm{T}} \Delta T\right)\left(c_{\mathrm{m}}-c_{\mathrm{m} 0}\right) t_{\mathrm{lin}} \\
& -\frac{1}{2} B_{0} B_{T} \Delta T t_{\mathrm{lin}} .
\end{aligned}
$$

We use this equation to calculate the derivatives $\frac{\partial c_{\mathrm{M}}}{\partial T}$ and $\frac{\partial c_{M}}{\partial c_{\mathrm{a}}}$. Evaluating these derivatives will involve the derivatives $\frac{\partial c_{\mathrm{m}}}{\partial T}$ and $\frac{\partial c_{\mathrm{m}}}{\partial c_{\mathrm{a}}}$. Since partial pressures across the air-sea interface equilibrate rapidly on the timescale of the model $\left(D=1 \mathrm{yr}^{-1}\right.$, Table 1$)$, we assume that $c_{\mathrm{a}} \approx p\left(c_{\mathrm{m}}, \Delta T\right)$, rearrange for $c_{\mathrm{m}}$, and then calculate the appropriate derivatives from the resulting equation.

We analytically estimate equilibrium versions of the timeintegrated feedback parameters of Friedlingstein et al. (2006) using a similar approach:

$\gamma_{\mathrm{L}}^{*}=\frac{\partial c_{\mathrm{t}}^{*}}{\partial T}$

$\beta_{\mathrm{L}}^{*}=\frac{\partial c_{\mathrm{t}}^{*}}{\partial c_{\mathrm{a}}}$

$\gamma_{\mathrm{O}}^{*}=\frac{\partial c_{\mathrm{M}}}{\partial T}$

$\beta_{\mathrm{O}}^{*}=\frac{\partial c_{\mathrm{M}}}{\partial c_{\mathrm{a}}}$.

Since the ocean component of the model has multiple processes that respond to temperature, some analytical forms were too complicated for easy visual inspection (Table A1). We derived approximate analytical feedbacks by comparing the magnitudes of terms in the numerator and denominator of the feedback measures by expanding in power series of $D_{T} T$ and $c_{\mathrm{a}} / c_{\mathrm{a} 0}$.

\subsection{Analytical feedback strengths based on carbon fluxes}

We estimate the direct feedback parameters as follows:

$\Gamma_{\mathrm{L}}^{*}=\left.\frac{\mathrm{d} c_{\mathrm{t}}}{\mathrm{d} t}\right|_{c_{\mathrm{a}}=c_{\mathrm{a} 0}} \frac{1}{\Delta T}$

$$
\begin{aligned}
& B_{\mathrm{L}}^{*}=\left.\frac{\mathrm{d} c_{\mathrm{t}}}{\mathrm{d} t}\right|_{\Delta T=0} \frac{1}{c_{\mathrm{a}}-c_{\mathrm{a} 0}} \\
& \Gamma_{\mathrm{O}}^{*}=\left.\frac{\mathrm{d} c_{\mathrm{M}}}{\mathrm{d} t}\right|_{c_{\mathrm{a}}=c_{\mathrm{a} 0}} \frac{1}{\Delta T} \\
& B_{\mathrm{O}}^{*}=\left.\frac{\mathrm{d} c_{\mathrm{M}}}{\mathrm{d} t}\right|_{\Delta T=0} \frac{1}{c_{\mathrm{a}}-c_{\mathrm{a} 0}} .
\end{aligned}
$$

Here $\mathrm{d} c_{\mathrm{t}} / \mathrm{d} t$ and $\mathrm{d} c_{\mathrm{M}} / \mathrm{d} t$ denote the atmosphere-land and atmosphere-ocean fluxes. The subscript $\Delta T=0$ denotes a biogeochemically coupled (and radiatively decoupled) simulation and $c_{\mathrm{a}}=c_{\mathrm{a} 0}$ denotes a radiatively coupled (and biogeochemically decoupled) simulation.

The values of the feedback parameters are strongly scenario dependent (Arora et al., 2013). To calculate the direct feedback parameters, we assume a standard $\mathrm{CO}_{2}$ quadrupling concentration pathway in order to compare our results with Arora et al. (2013). This scenario has $c_{\mathrm{a}}(t)=$ $c_{\mathrm{a} 0} a^{t}$, where $a=1.01$. In this scenario, $\frac{1}{c_{\mathrm{a}}} \frac{\mathrm{d} c_{\mathrm{a}}}{\mathrm{d} t}=\log a$ and, ignoring an initial exponential transient, $\frac{\mathrm{d} T}{\mathrm{~d} t}=\lambda \log a / \log 2$.

For the atmosphere-land carbon flux, the calculation is straightforward under the following assumptions. We assume that $\mathrm{NPP}_{0} / c_{\mathrm{t} 0} \gg \log a$ so that $c_{\mathrm{t}}$ tracks its carrying capacity $c_{\mathrm{t}} \approx K$ (Eq. 2). We also ignore land use change, so that $\frac{\mathrm{d} c_{\mathrm{t}}}{\mathrm{d} t} \approx \frac{\mathrm{d} K}{\mathrm{~d} t}$. Then we calculate $\left.\frac{\mathrm{d} K}{\mathrm{~d} t}\right|_{c_{\mathrm{a}}=c_{\mathrm{a} 0}}=\frac{\partial K}{\partial T} \frac{\mathrm{d} T}{\mathrm{~d} t}$ and $\left.\frac{\mathrm{d} K}{\mathrm{~d} t}\right|_{\Delta T=0}=\frac{\partial K}{\partial c_{\mathrm{a}}} \frac{\mathrm{d} c_{\mathrm{a}}}{\mathrm{d} t}$.

While the atmosphere-ocean flux could be read off directly from the first term of Eq. (6), this form is however not particularly useful. As it involves a small difference between two large quantities, $c_{\mathrm{a}}$ and $p\left(c_{\mathrm{m}}, \Delta T\right)$, the size of the difference can only be estimated from numerical results and gives no immediate insight into how it depends on parameters. Furthermore, we seek to compare our analytical results to the results presented by Arora et al. (2013), in which the feedback parameters are presented as functions of $c_{\mathrm{a}}$ or $\Delta T$ only (not $c_{\mathrm{m}}$ ).

We instead derive an approximation based on timescale separation as follows. The characteristic timescale of atmosphere-ocean diffusion is much faster than the solubility pump, biological pump, or human emissions into the atmosphere $\left(D \gg w_{0}, B_{0} / c_{\mathrm{m} 0}, \log a\right)$. Since atmosphere-ocean 
Table 3. Feedback analysis. Gains $(g)$, feedback factors $(F)$, time-integrated feedback parameters $(\gamma$ and $\beta$ ), and direct feedback parameters $(\Gamma$ and $B)$ were calculated analytically and numerically. Analytical ocean feedbacks are approximations of the exact forms in Table A1 (see Sect. 4.2). Exact forms were used to calculate numerical values. In this table, $p \equiv p\left(c_{\mathrm{m}}, T\right)$. Units of the climate-carbon integrated feedback parameters are $\mathrm{PgC} \mathrm{K} \mathrm{C}^{-1}$ and concentration-carbon integrated feedback parameters are $\operatorname{PgCppm}{ }^{-1}$. Ranges for analytical results are written in the form (value at start of simulation) to (value at end of simulation). Emissions scenarios are as indicated; land use emissions were assumed to be zero. From the results of simulations using the SRES A2 scenario we use $t_{\text {lin }} \approx 100$ corresponding to a period between the years 2000 and 2100 .

\begin{tabular}{|c|c|c|c|c|}
\hline Feedback measure & $\begin{array}{l}\text { Land climate- } \\
\text { carbon feedback }\end{array}$ & $\begin{array}{l}\text { Ocean climate- } \\
\text { carbon feedback }\end{array}$ & $\begin{array}{l}\text { Land conc.- } \\
\text { carbon feedback }\end{array}$ & $\begin{array}{l}\text { Ocean conc.- } \\
\text { carbon feedback }\end{array}$ \\
\hline \multirow{2}{*}{ Gain, analytical expression } & $\lambda c_{\mathrm{t} 0}\left(1+K_{\mathrm{C}} \log \frac{c_{\mathrm{a}}}{c_{\mathrm{a} 0}}\right) \log Q_{\mathrm{R}}$ & $c_{\mathrm{m}} D_{T} w_{0}$ & $c_{\mathrm{t} 0} K_{\mathrm{C}}$ & $c_{\mathrm{m}} w_{0} t_{\text {lin }}$ \\
\hline & $10 c_{\mathrm{a}} Q_{\mathrm{R}}^{\Delta T / 10} \log 2$ & $\begin{array}{l}\overline{c_{\mathrm{a}} \log 2}(\overline{2 r} \\
\left.+\frac{w_{0} w_{\mathrm{T}}\left(c_{\mathrm{m}}-c_{\mathrm{m} 0}\right)}{3}\right)\end{array}$ & $\overline{c_{\mathrm{a}} Q_{\mathrm{R}}^{\Delta T / 10}}$ & $2 c_{\mathrm{a}} r$ \\
\hline
\end{tabular}

Feedback factor (numerical scenario: SRES A2) ( $>1$ amplifies climate change; $<1$ dampens climate change)

$\begin{array}{lllll}\text { - estimate from analytical gain } & 1.81 \text { to } 1.18 & 1.01 \text { to } 1.09 & 0.51 \text { to } 0.81 & 0.89 \text { to } 0.84 \\ \text { - from simulation } & 1.15 & 1.10 & 0.80 & 0.73 \\ \text { - Zickfeld et al. (2011) } & 1.25 & 1.22 & 0.66 & 0.71\end{array}$

Time-integrated feedback parameter (numerical scenario: SRES A2) $(<0$ amplifies climate change; $>0$ dampens climate change)

\begin{tabular}{|c|c|c|c|c|}
\hline - analytical expression & $-\frac{c_{\mathrm{t} 0} \log Q_{\mathrm{R}}}{10 Q_{\mathrm{R}}^{\Delta T / 10}}$ & $\begin{array}{l}-B_{0} B_{T} \frac{t_{\text {lin }}}{2}-\frac{c_{\mathrm{m}} D_{T} w_{0} t_{\text {lin }}}{2 r} \\
-w_{0} w_{\mathrm{t}}\left(c_{\mathrm{m}}-c_{\mathrm{m} 0}\right) \frac{t_{\text {lin }}}{3}\end{array}$ & $\frac{c_{\mathrm{t} 0} K_{\mathrm{C}}}{c_{\mathrm{a}}}$ & $\frac{c_{\mathrm{m}} w_{0} t_{\mathrm{lin}}}{2 c_{\mathrm{a}} r}$ \\
\hline estimate from analytical form & -102 to -86 & -3 to -67 & 2.04 to 0.51 & 0.26 to 0.42 \\
\hline from simulation & -74 & -48 & 0.84 & 1.09 \\
\hline - Zickfeld et al. (2011) & -129 & -32 & 1.32 & 0.98 \\
\hline Friedlingstein et al. (2006) & $-79(-20$ to -177$)$ & $-30(-14$ to -67$)$ & $1.35(0.2$ to 2.8$)$ & 1.13 (0.8 to 1.6$)$ \\
\hline
\end{tabular}

Direct feedback parameter (numerical scenario: $\mathrm{CO}_{2}$ doubling) $(<0$ amplifies climate change; $>0$ dampens climate change)

- analytical expression $\quad-\frac{c_{\mathrm{t} 0} \lambda \log Q_{\mathrm{R}} \log a}{10 \Delta T \log 2}$

- estimate from analytical form Fig. A1a

- from simulation Fig. A1a

- Arora et al. (2013)

Non-linearity

$-0.43$ $-\frac{w_{0} c_{\mathrm{m} 0} D_{T}}{r}-B_{0} B_{T}$

Fig. A1b

Fig. A1b see text

$\begin{array}{lll}-0.11 & 0.03 & 0.03\end{array}$ diffusion is the fastest process, ocean mixed layer carbon content rapidly gains an equilibrium $c_{\mathrm{m}}=p^{-1}\left(c_{\mathrm{a}}, \Delta T\right)$ with respect to atmospheric carbon content, where $p^{-1}\left(c_{\mathrm{a}}, \Delta T\right)$ is the solution to $c_{\mathrm{a}}=p\left(c_{\mathrm{m}}, \Delta T\right)$. On the timescale of our model, the atmosphere-ocean flux is therefore controlled by the solubility and biological pumps, with diffusion providing a rapid coupling between ocean mixed layer and atmosphere. An approximation for the atmosphere-ocean flux is therefore $\mathrm{d} c_{\mathrm{M}} \mathrm{d} t^{-1} \approx w_{0}\left(1-w_{T} \Delta T\right)\left(p^{-1}\left(c_{\mathrm{a}}, \Delta T\right)-c_{\mathrm{m} 0}\right)-$ $B_{0} B_{T} T$, which upon substitution into the definitions of $B_{\mathrm{O}}^{*}$ and $\Gamma_{\mathrm{O}}^{*}$ gives the forms in Table A1. Taylor series expansions and L'Hôpital's rule were then used to derive the approximate forms in Table 3.

\subsection{Numerical estimation of feedback strengths}

In addition to the analytical approximations to carbon cycle feedbacks derived from our model, we also estimate feed- back factors from direct numerical simulations of our model. To compare the results of our model to previous studies, we use the following scenarios. To compare our results with the time-integrated feedback parameters reported by Friedlingstein et al. (2006) and the feedback factors and gains of Zickfeld et al. (2011), we employ the SRES A2 emissions scenario used in those articles. To compare our results with the direct feedback parameters of Arora et al. (2013), we use the same scenario used in that article in which $\mathrm{CO}_{2}$ concentration increases $1 \% \mathrm{yr}^{-1}$ until it quadruples (approximately 140 years). For each scenario, we perform four simulations:

1. Fully coupled simulation.

2. Completely uncoupled simulation, giving $c_{\mathrm{a}}^{\text {off }}(t)=$ $c_{\mathrm{a} 0}+\int^{t} E(t) \mathrm{d} t$ for the emissions-driven scenario and the specified concentration pathway for the concentrationdriven scenario. 
3. Biogeochemically coupled simulation. We switch off feedbacks involving temperature response to atmospheric $\mathrm{CO}_{2}$ by setting $\lambda=0$. Since our model contains no radiative forcing other than changes in $\mathrm{CO}_{2}$, temperature $\Delta T=0$ in this simulation. From this simulation we estimate the carbon-concentration feedback factors via land $F_{\mathrm{L}}=\Delta c_{\mathrm{a}}^{\text {on }} / \Delta c_{\mathrm{a}}^{\text {off }}=1-\Delta c_{\mathrm{t}} / \Delta c_{\mathrm{a}}^{\text {off }}$ and ocean $F_{\mathrm{O}}=\Delta c_{\mathrm{a}}^{\mathrm{on}} / \Delta c_{\mathrm{a}}^{\text {off }}=1-\Delta c_{\mathrm{M}} / \Delta c_{\mathrm{a}}^{\text {off }}$, timeintegrated feedback parameters $\beta_{\mathrm{L}}=\Delta c_{\mathrm{t}} / \Delta c_{\mathrm{a}}$ and $\beta_{\mathrm{O}}=\Delta c_{\mathrm{M}} / \Delta c_{\mathrm{a}}$, and direct feedback parameters $B_{\mathrm{L}}(t)=\frac{\mathrm{d} c_{\mathrm{t}}}{\mathrm{d} t} /\left(c_{\mathrm{a}}-c_{\mathrm{a} 0}\right)$ and $B_{\mathrm{O}}(t)=\frac{\mathrm{d} c_{\mathrm{M}}}{\mathrm{d} t} /\left(c_{\mathrm{a}}-c_{\mathrm{a} 0}\right)$.

4. Radiatively coupled simulation. We switch off feedbacks involving the carbon cycle, by setting $K_{\mathrm{C}}=0$ and changing the $c_{\mathrm{a}}$ in Eq. (6) to $c_{\mathrm{a} 0}$. From this simulation we estimate the carbon-climate feedback factors $F_{\mathrm{TL}}=1-\Delta c_{\mathrm{t}} / \Delta c_{\mathrm{a}}^{\text {off }}$ and $F_{\mathrm{TO}}=1-\Delta c_{\mathrm{M}} / \Delta c_{\mathrm{a}}^{\text {off }}$, time-integrated feedback parameters $\gamma_{\mathrm{L}}=\Delta c_{\mathrm{t}} / \Delta T$ and $\gamma_{\mathrm{O}}=\Delta c_{\mathrm{M}} / \Delta T$ following Arora et al. (2013), and direct feedback parameters $\Gamma_{\mathrm{L}}(t)=\frac{\mathrm{d} c_{\mathrm{t}}}{\mathrm{d} t} / \Delta T$ and $\Gamma_{\mathrm{O}}(t)=$ $\frac{\mathrm{d} c_{\mathrm{M}}}{\mathrm{d} t} / \Delta T$.

\subsection{Feedback non-linearity}

Zickfeld et al. (2011) found, in emissions-driven scenarios, that the fully coupled simulation sunk more terrestrial and marine carbon than the sum of the biogeochemically and radiatively coupled scenarios. They refer to this difference as the non-linearity of the feedback, with the land sink contributing $80 \%$ of the non-linearity and the ocean sink $20 \%$. Our analytical expressions for the feedbacks can be used to obtain an alternative measure of feedback non-linearity.

We evaluate the non-linearity in the ocean and land climate-carbon feedbacks using $F_{\mathrm{TO}}^{*}\left(c_{\mathrm{a}}, c_{\mathrm{m}}, c_{\mathrm{t}}, \Delta T\right)-$ $F_{\mathrm{TO}}^{*}\left(c_{\mathrm{a} 0}, c_{\mathrm{m} 0}, c_{\mathrm{t} 0}, \Delta T\right) \quad$ and $\quad F_{\mathrm{TL}}^{*}\left(c_{\mathrm{a}}, c_{\mathrm{m}}, c_{\mathrm{t}}, \Delta T\right)-$ $F_{\mathrm{TL}}^{*}\left(c_{\mathrm{a} 0}, c_{\mathrm{m} 0}, c_{\mathrm{t} 0}, \Delta T\right)$, respectively, where the $F^{*}\left(c_{\mathrm{a} 0}, c_{\mathrm{m} 0}, c_{\mathrm{t} 0}, \Delta T\right)$ are analytical approximations of feedback factors from a radiatively coupled simulation (all carbon stocks are fixed at pre-industrial levels). We evaluate the non-linearities in the ocean and land concentrationcarbon feedbacks using $F_{\mathrm{O}}^{*}\left(c_{\mathrm{a}}, c_{\mathrm{m}}, c_{\mathrm{t}}, \Delta T\right)-F_{\mathrm{O}}^{*}\left(c_{\mathrm{a}}, c_{\mathrm{m}}, c_{\mathrm{t}}, 0\right)$ and $F_{\mathrm{L}}^{*}\left(c_{\mathrm{a}}, c_{\mathrm{m}}, c_{\mathrm{t}}, \Delta T\right)-F_{\mathrm{L}}^{*}\left(c_{\mathrm{a}}, c_{\mathrm{m}}, c_{\mathrm{t}}, 0\right)$, respectively, where the $F^{*}\left(c_{\mathrm{a}}, c_{\mathrm{m}}, c_{\mathrm{t}}, 0\right)$ are analytical approximations of feedback factors from a biogeochemically coupled simulation (temperature is fixed at its pre-industrial level). These expressions indicate the effect of temperature and atmospheric carbon on the concentration-carbon and climate-carbon feedbacks, respectively, We used the SRES A2 scenario.

\section{Results and discussion}

\subsection{Model evaluation}

Most predictions of our model are within the range of model predictions produced for the IPCC's Fifth Assessment Re- port (Table 2). Our model estimates around $55 \mathrm{PgC}$ more historical land carbon uptake than the IPCC multi-model mean, possibly due to our simplification to a single land carbon pool. Because it omits radiative forcing due to greenhouse gases other than $\mathrm{CO}_{2}$, our model consistently underestimates future temperature changes, although in all except the RCP8.5 scenario the projections are within the IPCC model range. The purpose of our model is not to precisely predict future climate change, but to serve as an approximate, mechanistically based emulator of the carbon cycle component of Earth system models (see Sect. 2). If we choose parameters to fit historical observations rather than based on the best available knowledge about each process (see Sect. 3), then our results remain mostly within IPCC model range although ocean and land uptake are consistently above and below the IPCC multi-model mean, respectively (Table A2a). We conclude that the model emulates historical observations and future projections of Earth system models with sufficient accuracy for this purpose.

\subsection{Feedback analysis}

All feedback measures calculated directly from our stylised model simulations, as well as most of our analytically estimated feedback measures, are within a factor of 2 of the mean output from Earth system models reported by Friedlingstein et al. (2006) and Zickfeld et al. (2011) (Table 3; compare also Fig. A1 with Figs. 4-5 of Arora et al. (2013) for direct feedback parameters). This is a remarkably good agreement considering the highly stylised nature of our model. Furthermore, all of the numerically time-integrated feedback parameters from our stylised model are within the multi-model range reported by Friedlingstein et al. (2006). The agreement observed here serves as additional validation of our model as well as validation of the approximations used to calculate analytical feedback factors.

An exception to the close agreement is the ocean concentration-carbon feedback, with the analytically estimated feedback factor and time-integrated feedback parameter indicating a weaker negative feedback than the numerical estimates from our stylised model or Earth system models. This mismatch is primarily due to two approximations: one in the numerical simulation and one in the analytical approximation. The numerical approximation is that disconnecting climate feedbacks in the biogeochemically coupled simulation leaves less carbon available to be sunk into the ocean, placing the ocean feedback at a different point in the highly non-linear (as parameterised by the Revelle factor) ocean carbon uptake dynamics. The analytical approximation is that Eq. (21) underestimates carbon sunk into the deep ocean.

We used parameters (Table 1) based on the best available data about each process (see Sect. 3). With a set of parameters based instead on fit to historical changes (Table A2), the numerically estimated feedbacks became slightly stronger: that is, the already positive climate-carbon feedbacks be- 
came more positive and the already negative concentrationcarbon feedbacks more negative. The numerical feedback estimates retained, however, good agreement with analytical estimates as well as with previous numerical estimates by Friedlingstein et al. (2006) and Zickfeld et al. (2011). One exception was the ocean concentration-carbon feedback, for which the analytical estimate remained outside Friedlingstein et al.'s range as noted above, but the direct numerical estimate moved to also be outside their range. We conclude that our results are relatively insensitive to parameter values, though mechanistically based parameter values perform slightly better than fitted parameter values.

Focusing on the analytical expressions, we observe that the approximate analytical expressions for the three different feedback measures all have similar dependences on state variables and parameters. All measures of the land climate-carbon feedback have dependence of the form $c_{\mathrm{t} 0} \log Q_{\mathrm{R}} / Q_{\mathrm{R}}^{\Delta T / 10}$. The ocean climate-carbon feedbacks all have terms of the form $B_{0} B_{T}$ and $w_{0} D_{T} c_{m} / r$. The land concentration-carbon feedback has the form $c_{\mathrm{t} 0} K_{\mathrm{C}} / c_{\mathrm{a}}$ and the ocean concentration-carbon feedbacks have the form $w_{0} c_{m} / r c_{\mathrm{a}}$. We conclude that for each type of carbon cycle feedback, all three feedback formalisms detect similar features of the climate-carbon system.

The analytical expressions provide rapid insight into how feedback strengths depend on state variable and parameter values that could otherwise only be studied numerically or by qualitative reasoning. The analytical forms show that increasing Revelle factor $r$, as is likely to occur in an increasingly acidic ocean (Sabine et al., 2004), will decrease the strengths of ocean climate-carbon and concentration-carbon feedbacks. Weakening overturning circulation, via $w_{0}$, would also decrease the strength of the ocean carbon cycle feedbacks. On land, the parameters $Q_{\mathrm{R}}$ and $K_{\mathrm{C}}$ control the terrestrial carbon cycle feedbacks.

We can compare likely trends in feedback strengths from the analytical expressions for the direct feedback parameters. According to our model, the destabilising ocean climate-carbon feedback is almost constant, while the ocean concentration-carbon feedback weakens with $c_{\mathrm{m}}$ (since $\left.c_{\mathrm{m}} / c_{\mathrm{a}} \sim c_{\mathrm{m}}^{1-r}\right)$. Similarly, according to our model the destabilising land climate-carbon feedback will weaken less than the stabilising concentration-carbon feedback (under $\mathrm{CO}_{2}$ doubling, $\sim Q_{\mathrm{R}}^{-\Delta T / 10}$ weakens by $9 \%$ at the new temperature equilibrium while $\sim 1 / c_{\mathrm{a}}$ weakens by $50 \%$ ). This difference between the land climate-carbon and concentrationcarbon feedbacks stems from the differing curvatures of $K\left(c_{\mathrm{a}}, \Delta T\right)$ as a function of $\Delta T$ (close to linear) and $c_{\mathrm{a}}$ (concave). We conclude that under continued carbon emissions, according to our model, both land and ocean feedbacks will overall become more positive.

Where multiple processes contribute in parallel to a feedback, inspection of analytical forms can indicate the relative contributions of the different processes to the feedback. In the ocean component of the model, $\mathrm{CO}_{2}$ solubility, the biological pump, and the solubility pump are all temperature dependent and therefore contribute to the ocean climate-carbon feedback. Remarkably, all three processes contribute temperature dependences of a similar magnitude; we therefore list all three in the approximate analytical gain and timeintegrated feedback parameter in Table 3. The three terms represent temperature dependence of the biological pump, $\mathrm{CO}_{2}$ solubility, and the solubility pump.

\subsection{Feedback non-linearity}

As shown in Sect. 4.5, our analytical feedback expressions enable a new way of estimating feedback non-linearities that is not possible from direct numerical simulation. Since the sum of the four non-linearities is negative (Table 3), we conclude that summing feedbacks found by individual decoupled simulations will overestimate the atmospheric carbon levels, that is, underestimate land and ocean sinks. This result matches the findings of Zickfeld et al. (2011) and Matthews (2007). Terrestrial feedbacks contributed $83 \%$ of the total non-linearity in our model, compared to $80 \%$ reported by Zickfeld et al. (2011). Furthermore, we can distinguish the non-linearities in the climate-carbon and concentrationcarbon feedbacks. We found that the non-linearity in the terrestrial carbon-climate feedback was almost 4 times larger than any other (Table 3). By inspecting the analytical derivation of the gains we conclude that this dominance is likely due to a combination of three reasons: first, due to the sensitivity of temperature to carbon dioxide, $\partial T / \partial c_{\mathrm{a}}=\lambda / c_{\mathrm{a}} \log 2$, the carbon-climate feedbacks are much more sensitive to $c_{\mathrm{a}}$ than the concentration-carbon feedbacks are to $\Delta T$. Second, the non-linearity in the land climate-carbon feedback is larger than the ocean climate-carbon feedback because its feedback factor is larger and therefore more sensitive to changes in gain (see Eq. 13). Third, the century timescale of the simulation prevented ocean carbon dynamics, which generally take place on longer timescales, from being exhibited. We conclude that care must be taken when summing results for feedbacks from decoupled simulations, especially for simulations involving land feedbacks.

\section{Conclusions}

Earth system models span a wide range of complexity. Here, we constructed a highly stylised, globally aggregated climate-carbon cycle model. Despite the model's simplicity - just four state variables - the model emulated globally aggregated historical trends and future projections of Earth system models. The model's simple form allowed climatecarbon cycle feedbacks to be estimated analytically, providing mechanistic insight into these processes. For example, we showed that carbon-climate feedbacks are less sensitive than carbon-concentration feedbacks; on land, this is due to the shape of $K\left(c_{\mathrm{a}}, \Delta T\right)$. The simple but accurate climate- 
carbon cycle model could be a starting point for model-based investigations of Earth system processes that are too poorly understood to be incorporated in more comprehensive models.

Stylised models such as ours have significant value in policy contexts. When confronted with difficult policy decisions involving long time periods and significant uncertainty, collaborative work with scientists allows policymakers to identify and clarify the impacts of various policy actions. In this context, the utility of a model is to increase stakeholders' understanding of a system and its dynamics under various conditions (Voinov and Bousquet, 2010; Anderies, 2005). This is in stark contrast to the use of more comprehensive models to predict impacts of policies in which mechanisms underlying dynamics and trade-offs are not transparent and quick explorations with stakeholders are not practical. The utility of a stylised model is in facilitating a learning process rather than in "accurately" predicting outcomes.

We foresee at least two strands of valuable future research based on the climate-carbon cycle model developed in this paper. First, our climate-carbon cycle model could be extended by including further processes relevant on different timescales of interest for Earth system analysis. This would enable a more in-depth analytical analysis of the feedback strengths and gains relating to other aspects of Earth system dynamics, such as the Earth's energy balance, carbon storage in the tropics compared to extratropics, albedo changes, the cryosphere, nutrient cycles, and even societal feedbacks. The task of characterising the Anthropocene as an epoch could thus move beyond qualitative comparison of human-impact trends to an improved characterisation of the feedbacks that maintain different Earth system "regimes". The effects on feedback strengths of different functional forms, such as the fertilisation effect $K_{\mathrm{C}}$, and how to constrain these functional forms from data could also be investigated and could yield insight into the continued divergence of Earth system model projections.
Second, the model could comprise a workbench for the systemic understanding of planetary boundary interactions and hence generate crucial insights into the structure of the safe operating space for humanity delineated by the planetary boundaries (Rockström et al., 2009; Steffen et al., 2015). Such extensions should focus on linking the core abiotic and biotic dimensions of the planetary boundary framework. The present lack of well-developed model representations of the dynamics and ecosystem structure of biosphere diversity, heterogeneity, and resilience, despite ongoing efforts in this direction (Purves et al., 2013; Bartlett et al., 2016; Sakschewski et al., 2016), emphasises the need for a more conceptual understanding of biosphere integrity, its vulnerability to anthropogenic perturbation, and its role for Earth system resilience.

Data availability. Input parameters are listed in Table 2 and time series inputs are from publicly available data as listed in Sect. 3. 
Appendix A

(a)

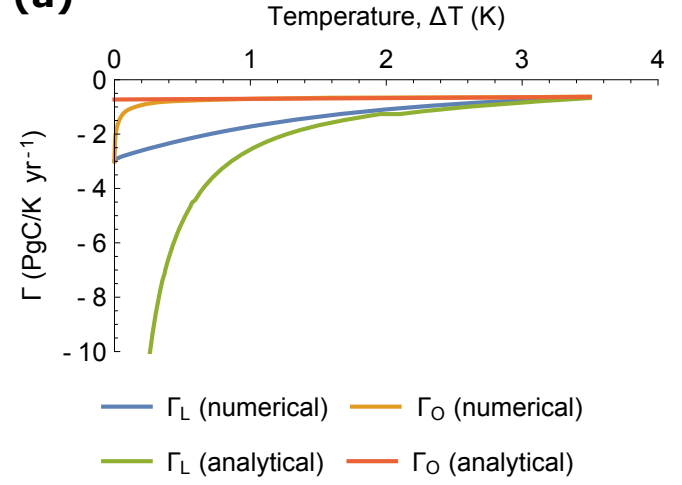

(b)

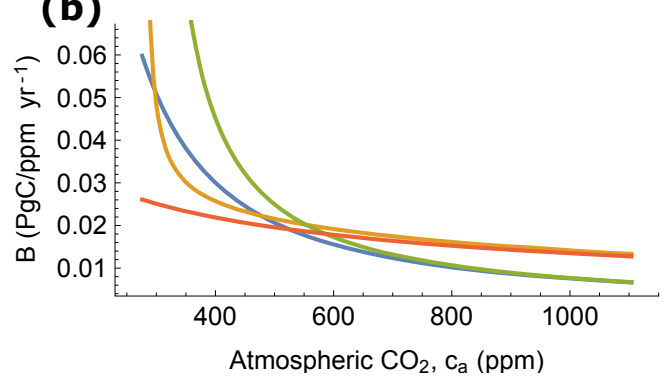

$-\mathrm{B}_{\mathrm{L}}$ (numerical) $-\mathrm{B}_{\mathrm{O}}$ (numerical)

$-\mathrm{B}_{\mathrm{L}}$ (analytical) $-\mathrm{B}_{\mathrm{O}}$ (analytical)

Figure A1. Direct feedback parameters, (a) climate-carbon feedbacks, and (b) concentrationcarbon feedbacks.

Table A1. Exact forms for ocean feedbacks.

\begin{tabular}{lll}
\hline Feedback measure & Ocean climate-carbon feedback & Ocean concentration-carbon feedback \\
\hline Gain & $\frac{\lambda}{c_{\mathrm{a}} \log 2}\left[\frac{B_{0} B_{T} t_{\mathrm{lin}}}{2}+\frac{t_{\mathrm{lin}}}{3} w_{0} w_{\mathrm{t}}\left(c_{\mathrm{m}}-c_{\mathrm{m} 0}\right)\right.$ & $-\frac{c_{\mathrm{m}}}{c_{\mathrm{a}} r}\left(1+w_{0} t_{\mathrm{lin}}\left(\frac{1}{2}-\frac{w_{\mathrm{T}} \Delta T}{3}\right)\right)$ \\
& $\left.+\frac{c_{\mathrm{m}} D_{T}}{r\left(1-D_{T} \Delta T\right)}\left(1+w_{0} t_{\operatorname{lin}}\left(\frac{1}{2}-\frac{w_{\mathrm{T}} \Delta T}{3}\right)\right)\right]$ & \\
\hline Time-integrated feedback & $-\frac{c_{\mathrm{m}} D_{T}}{r\left(1-D_{T} \Delta T\right)}\left(1+w_{0} t_{\operatorname{lin}}\left(\frac{1}{2}-\frac{w_{\mathrm{T}} \Delta T}{3}\right)\right)$ & $\frac{c_{\mathrm{m}}}{c_{\mathrm{a}} r}\left(1+w_{0} t_{\operatorname{lin}}\left(\frac{1}{2}-\frac{w_{\mathrm{T}} \Delta T}{3}\right)\right)$ \\
parameter & $-\frac{B_{0} B_{T} t_{\mathrm{lin}}}{2}-\frac{t_{\mathrm{lin}}}{3} w_{0} w_{\mathrm{t}}\left(c_{\mathrm{m}}-c_{\mathrm{m} 0)}\right.$ & \\
\hline & $\frac{w_{0}\left(1-w_{\mathrm{T}} \Delta T\right) c_{\mathrm{m} 0}\left(\left(1-D_{T} \Delta T\right)^{\frac{1}{r}}-1\right)}{\Delta T}-B_{0} B_{T}$ & $\frac{w_{0} c_{\mathrm{m} 0}\left(\left(\frac{c_{\mathrm{a}}}{c_{\mathrm{a} 0}}\right)^{\frac{1}{r}}-1\right)}{c_{\mathrm{a}}-c_{\mathrm{a} 0}}$ \\
\hline
\end{tabular}


Table A2. Testing parameters fitted to historical data. The following changes to parameter values were made to those listed in Table 1: $K_{\mathrm{C}}=$ $0.25, Q_{\mathrm{R}}=2.45, \lambda=1.91 \mathrm{~K}, w_{0}=0.185 \mathrm{yr}^{-1}$. (a) Historical and projected changes of carbon stocks. See Table 2 for further information on how the figures were calculated and sources for model comparison. (b) Feedback analysis. See Table 3 for further information. Analytical forms are omitted here.

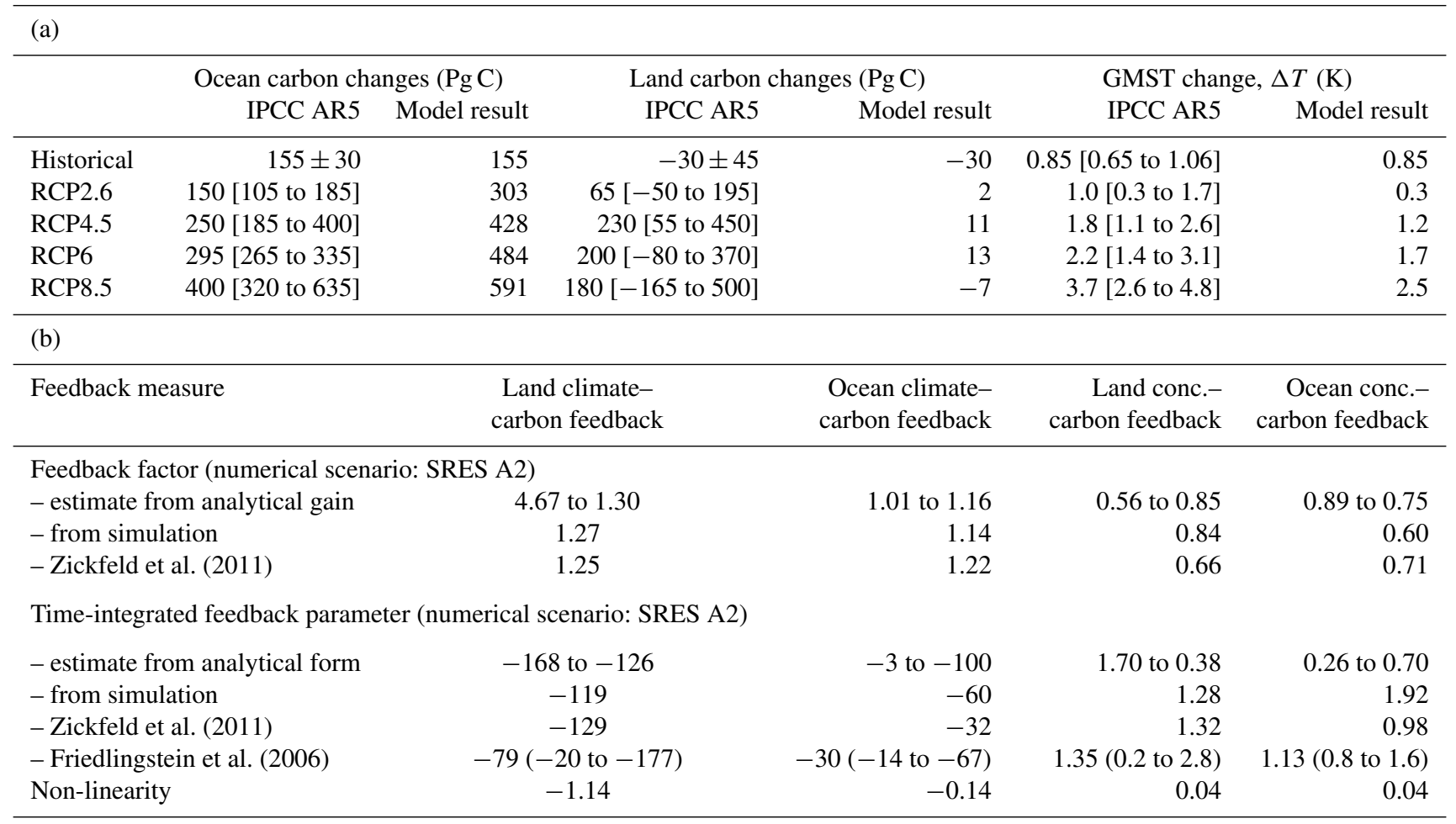


Author contributions. SJL, JMA, SEC, JFD, IF, KR, JR, and WS designed the research. SJL, JFD, IF, TG, and CB constructed the model. SJL analysed the model. All authors wrote the paper.

Competing interests. The authors declare that they have no conflict of interest.

Special issue statement. This article is part of the special issue "Social dynamics and planetary boundaries in Earth system modelling". It is not associated with a conference.

Acknowledgements. The research leading to these results has received funding from the Stordalen Foundation via the Planetary Boundary Research Network (PB.net), the Earth League's EarthDoc programme, the Leibniz Association (project DOMINOES), European Research Council Synergy project Imbalance-P (grant ERC-2013-SyG-610028), project grant 2014-589 from the Swedish Research Council Formas, and a core grant to the Stockholm Resilience Centre by Mistra. We thank Malin Ödalen for her comments on the paper.

Edited by: Axel Kleidon

Reviewed by: Martin Heimann and Chris Jones

\section{References}

Alexandrov, G., Oikawa, T., and Yamagata, Y.: Climate dependence of the $\mathrm{CO}_{2}$ fertilization effect on terrestrial net primary production, Tellus B, 55, 669-675, 2003.

Anderies, J. M.: Minimal models and agroecological policy at the regional scale: an application to salinity problems in southeastern Australia, Reg. Environ. Change, 5, 1-17, 2005.

Anderies, J. M., Carpenter, S. R., Steffen, W., and Rockström, J.: The topology of non-linear global carbon dynamics: from tipping points to planetary boundaries, Environ. Res. Lett., 8, 044048, https://doi.org/10.1088/1748-9326/8/4/044048, 2013.

Arora, V. K., Boer, G. J., Friedlingstein, P., Eby, M., Jones, C. D., Christian, J. R., Bonan, G., Bopp, L., Brovkin, V., Cadule, P., Bala, G., John, J., Jones, C., Joos, F., Kato, T., Kawamiya, M., Knorr, W., Lindsay, K., Matthews, H. D., Raddatz, T., Rayner, P., Reick, C., Roeckner, E., Schnitzler, K.-G., Schnur, R., Strassmann, K., Weaver, A. J., Yoshikawa, C., and Zeng, N.: Carbonconcentration and carbon-climate feedbacks in CMIP5 Earth system models, J. Climate, 26, 5289-5314, 2013.

Bacastow, R., Keeling, C. D., Woodwell, G., and Pecan, E.: Atmospheric carbon dioxide and radiocarbon in the natural carbon cycle, II. Changes from AD 1700 to 2070 as deduced from a geochemical model, Tech. rep., Univ. of California, San Diego, La Jolla; Brookhaven National Lab., Upton, NY, USA, 1973.

Bartlett, L. J., Newbold, T., Purves, D. W., Tittensor, D. P., and Harfoot, M. B.: Synergistic impacts of habitat loss and fragmentation on model ecosystems, P. Roy. Soc. B, 283, 20161027, https://doi.org/10.1098/rspb.2016.1027, 2016.

Bernardello, R., Marinov, I., Palter, J. B., Sarmiento, J. L., Galbraith, E. D., and Slater, R. D.: Response of the ocean natural carbon storage to projected twenty-first-century climate change, J. Climate, 27, 2033-2053, 2014.

Boer, G. and Arora, V.: Temperature and concentration feedbacks in the carbon cycle, Geophys. Res. Lett., 36, L02704, https://doi.org/10.1029/2008GL036220, 2009.

Boer, G. and Arora, V.: Feedbacks in emission-driven and concentration-driven global carbon budgets, J. Climate, 26, 3326-3341, 2013.

Bopp, L., Resplandy, L., Orr, J. C., Doney, S. C., Dunne, J. P., Gehlen, M., Halloran, P., Heinze, C., Ilyina, T., Séférian, R., Tjiputra, J., and Vichi, M.: Multiple stressors of ocean ecosystems in the 21st century: projections with CMIP5 models, Biogeosciences, 10, 6225-6245, https://doi.org/10.5194/bg-106225-2013, 2013.

Ciais, P., Sabine, C., Bala, G., Bopp, L., Brovkin, V., Canadell, J., Chhabra, A., DeFries, R., Galloway, J., Heimann, M., Jones, C., LeQuéré, C., Myneni, R., Piao, S., and Thornton, P.: Carbon and Other Biogeochemical Cycles, book section 6, Cambridge University Press, Cambridge, UK and New York, NY, USA, 465570, https://doi.org/10.1017/CBO9781107415324.015, 2013.

Collins, M., Knutti, R., Arblaster, J., Dufresne, J.-L., Fichefet, T., Friedlingstein, P., Gao, X., Gutowski, W., Johns, T., Krinner, G., Shongwe, M., Tebaldi, C., Weaver, A., and Wehner, M.: Long-term Climate Change: Projections, Commitments and Irreversibility, book section 12, Cambridge University Press, Cambridge, UK and New York, NY, USA, 1029-1136, https://doi.org/10.1017/CBO9781107415324.024, 2013.

Flato, G., Marotzke, J., Abiodun, B., Braconnot, P., Chou, S., Collins, W., Cox, P., Driouech, F., Emori, S., Eyring, V., Forest, C., Gleckler, P., Guilyardi, E., Jakob, C., Kattsov, V., Reason, C., and Rummukainen, M.: Evaluation of Climate Models, book section 9, Cambridge University Press, Cambridge, UK and New York, NY, USA, 741-866, https://doi.org/10.1017/CBO9781107415324.020, 2013.

Friedlingstein, P.: Carbon cycle feedbacks and future climate change, Philos. T. Roy. Soc. A, 373, 20140421, https://doi.org/10.1098/rsta.2014.0421, 2015.

Friedlingstein, P., Cox, P., Betts, R., Bopp, L., Von Bloh, W., Brovkin, V., Cadule, P., Doney, S., Eby, M., Fung, I., Bala, G., John, J., Jones, C., Joos, F., Kato, T., Kawamiya, M., Knorr, W., Lindsay, K., Matthews, H. D., Raddatz, T., Rayner, P., Reick, C., Roeckner, E., Schnitzler, K.-G., Schnur, R., Strassmann, K., Weaver, A. J., Yoshikawa, C., and Zeng, N.: Climate-carbon cycle feedback analysis: results from the C4MIP model intercomparison, J. Climate, 19, 3337-3353, 2006.

Gasser, T., Ciais, P., Boucher, O., Quilcaille, Y., Tortora, M., Bopp, L., and Hauglustaine, D.: The compact Earth system model OSCAR_v2.2: description and first results, Geosci. Model Dev., 10, 271-319, https://doi.org/10.5194/gmd-10-271-2017, 2017a.

Gasser, T., Peters, G. P., Fuglestvedt, J. S., Collins, W. J., Shindell, D. T., and Ciais, P.: Accounting for the climate-carbon feedback in emission metrics, Earth Syst. Dynam., 8, 235-253, https://doi.org/10.5194/esd-8-235-2017, 2017b.

Goodwin, P., Williams, R. G., Follows, M. J., and Dutkiewicz, S.: Ocean-atmosphere partitioning of anthropogenic carbon dioxide on centennial timescales, Global Biogeochem. Cy., 21, GB1014, https://doi.org/10.1029/2006GB002810, 2007.

Gregory, J. M., Jones, C., Cadule, P., and Friedlingstein, P.: Quantifying carbon cycle feedbacks, J. Climate, 22, 5232-5250, 2009. 
Gregory, J. M., Andrews, T., and Good, P.: The inconstancy of the transient climate response parameter under increasing $\mathrm{CO}_{2}$, Philos. T. Roy. Soc. A, 373, 20140417 https://doi.org/10.1098/rsta.2014.0417, 2015.

Hansen, J., Lacis, A., Rind, D., Russell, G., Stone, P., Fung, I., Ruedy, R., and Lerner, J.: Climate sensitivity: analysis of feedback mechanisms, in: Climate Processes and Climate Sensitivity, AGU Geophysical Monograph 29, Maurice Ewing Vol. 5, edited by: Hansen, J. E. and Takahashi, T., Washington, D.C., 130-163, 1984.

Harman, I. N., Trudinger, C. M., and Raupach, M. R.: SCCMthe Simple Carbon-Climate Model: Technical Documentation, CAWCR Technical Report No. 047, The Centre for Australian Weather and Climate Research, Canberra, 2011.

Hartmann, D., Klein Tank, A., Rusticucci, M., Alexander, L., Brönnimann, S., Charabi, Y., Dentener, F., Dlugokencky, E., Easterling, D., Kaplan, A., Soden, B., Thorne, P., Wild, M., and Zhai, P.: Observations: Atmosphere and Surface, book section 2, Cambridge University Press, Cambridge, UK and New York, NY, USA, p. 159-254, https://doi.org/10.1017/CBO9781107415324.008, 2013.

Jones, D. C., Ito, T., Takano, Y., and Hsu, W.-C.: Spatial and seasonal variability of the air-sea equilibration timescale of carbon dioxide, Global Biogeochem. Cy., 28, 1163-1178, 2014.

Joos, F., Bruno, M., Fink, R., Siegenthaler, U., Stocker, T. F., Le Quere, C., and Sarmiento, J. L.: An efficient and accurate representation of complex oceanic and biospheric models of anthropogenic carbon uptake, Tellus B, 48, 397-417, 1996.

Joos, F., Roth, R., Fuglestvedt, J. S., Peters, G. P., Enting, I. G., von Bloh, W., Brovkin, V., Burke, E. J., Eby, M., Edwards, N. R., Friedrich, T., Frölicher, T. L., Halloran, P. R., Holden, P. B., Jones, C., Kleinen, T., Mackenzie, F. T., Matsumoto, K., Meinshausen, M., Plattner, G.-K., Reisinger, A., Segschneider, J., Shaffer, G., Steinacher, M., Strassmann, K., Tanaka, K., Timmermann, A., and Weaver, A. J.: Carbon dioxide and climate impulse response functions for the computation of greenhouse gas metrics: a multi-model analysis, Atmos. Chem. Phys., 13, 27932825, https://doi.org/10.5194/acp-13-2793-2013, 2013.

Kamiuto, K.: A simple global carbon-cycle model, Energy, 19, 825829, 1994.

Kellie-Smith, O. and Cox, P. M.: Emergent dynamics of the climate-economy system in the Anthropocene, Philos. T. Roy. Soc. A, 369, 868-886, 2011.

Köchy, M., Hiederer, R., and Freibauer, A.: Global distribution of soil organic carbon - Part 1: Masses and frequency distributions of SOC stocks for the tropics, permafrost regions, wetlands, and the world, SOIL, 1, 351-365, https://doi.org/10.5194/soil-1-3512015, 2015.

Körner, C.: Carbon limitation in trees, J. Ecol., 91, 4-17, 2003.

Kriegler, E., Hall, J. W., Held, H., Dawson, R., and Schellnhuber, H. J.: Imprecise probability assessment of tipping points in the climate system, P. Natl. Acad. Sci. USA, 106, 5041-5046, 2009.

Lenton, T. M.: Land and ocean carbon cycle feedback effects on global warming in a simple Earth system model, Tellus B, 52, 1159-1188, 2000.

Lenton, T. M., Held, H., Kriegler, E., Hall, J. W., Lucht, W., Rahmstorf, S., and Schellnhuber, H. J.: Tipping elements in the Earth's climate system, P. Natl. Acad. Sci. USA, 105, 1786-1793, 2008.
Le Quéré, C., Andrew, R. M., Canadell, J. G., Sitch, S., Korsbakken, J. I., Peters, G. P., Manning, A. C., Boden, T. A., Tans, P. P., Houghton, R. A., Keeling, R. F., Alin, S., Andrews, O. D., Anthoni, P., Barbero, L., Bopp, L., Chevallier, F., Chini, L. P., Ciais, P., Currie, K., Delire, C., Doney, S. C., Friedlingstein, P., Gkritzalis, T., Harris, I., Hauck, J., Haverd, V., Hoppema, M., Klein Goldewijk, K., Jain, A. K., Kato, E., Körtzinger, A., Landschützer, P., Lefèvre, N., Lenton, A., Lienert, S., Lombardozzi, D., Melton, J. R., Metzl, N., Millero, F., Monteiro, P. M. S., Munro, D. R., Nabel, J. E. M. S., Nakaoka, S.-I., O’Brien, K., Olsen, A., Omar, A. M., Ono, T., Pierrot, D., Poulter, B., Rödenbeck, C., Salisbury, J., Schuster, U., Schwinger, J., Séférian, R., Skjelvan, I., Stocker, B. D., Sutton, A. J., Takahashi, T., Tian, H., Tilbrook, B., van der Laan-Luijkx, I. T., van der Werf, G. R., Viovy, N., Walker, A. P., Wiltshire, A. J., and Zaehle, S.: Global Carbon Budget 2016, Earth Syst. Sci. Data, 8, 605-649, https://doi.org/10.5194/essd-8-605-2016, 2016.

Matthews, H. D.: Implications of $\mathrm{CO}_{2}$ fertilization for future climate change in a coupled climate-carbon model, Global Change Biol., 13, 1068-1078, 2007.

Meinshausen, M., Raper, S. C. B., and Wigley, T. M. L.: Emulating coupled atmosphere-ocean and carbon cycle models with a simpler model, MAGICC6 - Part 1: Model description and calibration, Atmos. Chem. Phys., 11, 1417-1456, https://doi.org/10.5194/acp-11-1417-2011, 2011a.

Meinshausen, M., Smith, S. J., Calvin, K., Daniel, J. S., Kainuma, M., Lamarque, J., Matsumoto, K., Montzka, S., Raper, S., Riahi, K., Thomson, A., Velders, G. J. M., and van Vuuren, D. P. P.: The RCP greenhouse gas concentrations and their extensions from 1765 to 2300, Climatic Change, 109, 213-241, $2011 b$.

Meinshausen, M., Wigley, T. M. L., and Raper, S. C. B.: Emulating atmosphere-ocean and carbon cycle models with a simpler model, MAGICC6 - Part 2: Applications, Atmos. Chem. Phys., 11, 1457-1471, https://doi.org/10.5194/acp-111457-2011, 2011c.

NOAA: Climate at a Glance: Global Time Series, Tech. rep., NOAA National Centers for Environmental information, available at: http://www.ncdc.noaa.gov/cag/, last access: 16 May 2018.

Purves, D., Scharlemann, J. P., Harfoot, M., Newbold, T., Tittensor, D. P., Hutton, J., and Emmott, S.: Ecosystems: time to model all life on Earth, Nature, 493, 295-297, 2013.

Raich, J. W., Potter, C. S., and Bhagawati, D.: Interannual variability in global soil respiration, 1980-1994, Global Change Biol., 8, 800-812, 2002.

Randers, J., Golüke, U., Wenstøp, F., and Wenstøp, S.: A userfriendly earth system model of low complexity: the ESCIMO system dynamics model of global warming towards_2100, Earth Syst. Dynam., 7, 831-850, https://doi.org/10.5194/esd-7-8312016, 2016.

Raupach, M. R.: The exponential eigenmodes of the carbon-climate system, and their implications for ratios of responses to forcings, Earth Syst. Dynam., 4, 31-49, https://doi.org/10.5194/esd-4-312013, 2013.

Ricke, K. L. and Caldeira, K.: Maximum warming occurs about one decade after a carbon dioxide emission, Environ. Res. Lett., 9, 124002, https://doi.org/10.1088/1748-9326/9/12/124002, 2014.

Rockström, J., Steffen, W., Noone, K., Persson, Å., Chapin, F. S., Lambin, E. F., Lenton, T. M., Scheffer, M., Folke, C., Schellnhu- 
ber, H. J., Nykvist, B., de it, C. A., Hughes, T., van der Leeuw, S., Rodhe, H., Sörlin, S., Snyder, P. K., Costanza, R., Svedin, U., Falkenmark, M., Karlberg, L., Corell, R. W., Fabry, V. J., Hansen, J., Walker, B., Liverman, D., Richardson, K., Crutzen, P., and Foley, J. A.: A safe operating space for humanity, Nature, 461, 472-475, 2009.

Sabine, C. L., Feely, R. A., Gruber, N., Key, R. M., Lee, K., Bullister, J. L., Wanninkhof, R., Wong, C., Wallace, D. W., Tilbrook, B., Millero, F. J., Peng, T.-H., Kozyr, A., Ono, T., and Rios, A. F.: The oceanic sink for anthropogenic $\mathrm{CO}_{2}$, Science, 305, 367-371, 2004.

Sakschewski, B., von Bloh, W., Boit, A., Poorter, L., PeñaClaros, M., Heinke, J., Joshi, J., and Thonicke, K.: Resilience of Amazon forests emerges from plant trait diversity, Nat. Clim. Change, 6, 1032-1036, https://doi.org/10.1038/nclimate3109, 2016.

Schellnhuber, H. J., Rahmstorf, S., and Winkelmann, R.: Why the right climate target was agreed in Paris, Nat. Clim. Change, 6, 649-653, 2016.

Sigman, D. M. and Boyle, E. A.: Glacial/interglacial variations in atmospheric carbon dioxide, Nature, 407, 859-869, 2000.

Sitch, S., Friedlingstein, P., Gruber, N., Jones, S. D., MurrayTortarolo, G., Ahlström, A., Doney, S. C., Graven, H., Heinze, C., Huntingford, C., Levis, S., Levy, P. E., Lomas, M., Poulter, B., Viovy, N., Zaehle, S., Zeng, N., Arneth, A., Bonan, G., Bopp, L., Canadell, J. G., Chevallier, F., Ciais, P., Ellis, R., Gloor, M., Peylin, P., Piao, S. L., Le Quéré, C., Smith, B., Zhu, Z., and Myneni, R.: Recent trends and drivers of regional sources and sinks of carbon dioxide, Biogeosciences, 12, 653679, https://doi.org/10.5194/bg-12-653-2015, 2015.

Steffen, W., Richardson, K., Rockström, J., Cornell, S. E., Fetzer, I., Bennett, E. M., Biggs, R., Carpenter, S. R., de Vries, W., de Wit, C. A., Folke, C., Gerten, D., Heinke, J., Mace, G. M., Persson, L. M., Ramanathan, V., Reyers, B., and Sörlin, S.: Planetary boundaries: Guiding human development on a changing planet, Science, 347, 1259855, https://doi.org/10.1126/science.1259855, 2015.
Takahashi, T., Olafsson, J., Goddard, J. G., Chipman, D. W., and Sutherland, S. C.: Seasonal variation of $\mathrm{CO}_{2}$ and nutrients in the high-latitude surface oceans: a comparative study, Global Biogeochem. Cy., 7, 843-878, 1993.

Voinov, A. and Bousquet, F.: Modelling with stakeholders, Environ. Modell. Softw., 25, 1268-1281, 2010.

Volk, T. and Hoffert, M. I.: Ocean carbon pumps: Analysis of relative strengths and efficiencies in ocean-driven atmospheric $\mathrm{CO}_{2}$ changes, in: The Carbon Cycle and Atmospheric CO: Natural Variations Archean to Present, edited by: Sundquist, E. T. and Broecker, W. S., American Geophysical Union, Washington, D.C., 99-110, 1985.

Wieder, W. R., Cleveland, C. C., Smith, W. K., and Todd-Brown, K.: Future productivity and carbon storage limited by terrestrial nutrient availability, Nat. Geosci., 8, 441-444, 2015.

Williams, R. G., Goodwin, P., Roussenov, V. M., and Bopp, L.: A framework to understand the transient climate response to emissions, Environ. Res. Lett., 11, 015003, https://doi.org/10.1088/1748-9326/11/1/015003, 2016.

$\mathrm{Xu}, \mathrm{M}$. and Shang, H.: Contribution of soil respiration to the global carbon equation, J. Plant Physiol., 203, 16-28, 2016.

Zaehle, S., Friedlingstein, P., and Friend, A. D.: Terrestrial nitrogen feedbacks may accelerate future climate change, Geophys. Res. Lett., 37, L01401, https://doi.org/10.1029/2009GL041345, 2010.

Zickfeld, K., Eby, M., Matthews, H. D., Schmittner, A., and Weaver, A. J.: Nonlinearity of carbon cycle feedbacks, J. Climate, 24, 4255-4275, 2011. 